\title{
A Framework for Relationships in Outsourcing: Contract Management Archetypes
}

\author{
Sara Cullen, Graeme Shanks and Michael Davern \\ The University of Melbourne \\ cullens@unimelb.edu.au
}

\begin{abstract}
Outsourcing engagements are defined by contracts, but personal relationships drive success. In this paper, we propose a set of behavior archetypes and use them within four action-research cases that altered behavior to achieve positive outcomes. The results suggest that a successful outsourcing engagement can be derived through adaptation of well-considered behavioral approaches rather than contracting techniques.
\end{abstract}

\section{Introduction}

Since 1989, when Kodak outsourced IT in a landmark initiative, there has been significant growth in the market. In the UK alone, the outsourcing industry represents $8 \%$ of gross domestic product, employs $10 \%$ of the workforce, and contributes $11 \%$ of tax revenues [1]. Industry analysts estimated the size of the ITO/BPO (IT/business process outsourcing) market at \$US952 billion in 2013 with compound annual growth expected to be between $3.5 \%$ and 5.5\% from 2013-2017 [2].

Growth continues despite ITO agreements facing significant difficulties. Over $55 \%$ of ITO initiatives fail or do not meet expectations. Despite this, $61 \%$ of executives would transition to another outsourcing provider rather than move services inhouse [3].

With $72 \%$ of organizations outsourcing IT [4], outsourcing will remain prominent in the management of IT. As a result, academic studies have been carried out over the past 25 years to better understand what factors influence outcomes [5,6].

An early focus was on the nature of the contract and had conflicting conclusions. For example, consider long-term vs. short-term contracts. Earl argues that uncertainty involving IT precludes having a long-term contract [7]. Klepper and Jones argue that long-term contracts enable the provider to learn about the customer and for both to establish trust [8]. Lacity and Willcocks found that short-term contracts

\author{
Leslie Willcocks \\ London School of Economics and Political Science \\ l.p.willcocks@lse.ac.uk
}

yield cost savings [9]; Lee et al. found the reverse [10].

More recent studies have identified that managing the relationship between the parties plays a crucial role in outsourcing outcomes [11], 12]. This covers the softer side of outsourcing management such as trust, commitment, and knowledge sharing. This is a challenging area as $76 \%$ of companies found vendor management effort and costs to be much higher than expected [13].

Most pertinent to this paper is that trust and shared values are crucial at the individual level, not just the organizational level [14]. In fact, successful outsourcing may be more dependent on the people who execute it than on inter-firm relationships [15]. It is at this individual level that we are proposing a set of behavioral archetypes to describe and interpret behaviors in outsourcing relationships. In doing so, both buyer and seller firms can review and adjust their management to achieve positive outcomes.

Accordingly, the research question addressed in this study is: What are the behavioral archetypes observed amongst outsourcing actors and how can they be adapted to create effective outsourcing relationships?

To answer this question we first describe a framework comprising a set of six observed archetypes. We then present four cases of action research that use the archetypes to diagnose problems and challenges with outsourcing relationships.

The paper is structured as follows. First, we discuss the background, including the importance of the relationship overall and at an interpersonal level. Next, we describe the archetypes and the research approach. We then present four action research cases using the archetypes and the lessons learned. Lastly, we discuss cross-case lessons and implications for practice and research. 


\section{Background}

\subsection{The importance of relationships}

Practitioners and researchers alike argue that the key to success is good working relationships. On the practitioner side, Cullen has relationships as one of four crucial goal categories in her contract scorecard, in addition to financial, service, and strategic goals [16]. On the academic side, Lacity and Willcocks coded 132 outsourcing studies on governance and its effect on outcomes. In $94 \%$ of the findings, higher levels of relational governance were associated with higher levels of success [17].

Then there is the work on the role of the relationship in customer retention and growth. For a provider to keep a contract, performing is not enough. There needs to be a good relationship as well as prohibitive switching costs. A study of 160 IT managers involved with outsourced applications development found those that had switched providers had high product and service quality, but low relationship quality and switching costs and those that backsourced had low levels on all four variables [18]. Moreover, strong relationships when combined with good service delivery records, inclined a customer to outsource more to the provider [19].

\subsection{Relationships at an interpersonal level}

The individual level of analysis is important for insight into the relational aspect of outsourcing considering that the majority of day-to-day activities are carried out at an individual level [14]. The exchanges that occur at an individual level have been shown to be stronger indicators in measuring the strength of a relationship than on a firm level [15].

In a study of 139 pairings between customer and provider leaders managing an outsourcing relationship, Lacity and Willcocks found bi-party pairs who were both experienced leaders, but the combination simply did not work [20]. The psychological contracts were not aligned. Hill et al. found that the perceived violation of the psychological contract due to the customer's behavior increased opportunistic behavior by the provider and thus hindered the formation of a long-term partnership [21].

Recognizing that relationships formed at the firm level are first reached at the individual level, the archetypes proposed operate first with individuals, which can then be brought together to examine larger groupings (i.e. team and firm levels).

\section{Behavioral archetypes}

\subsection{Nature of the archetype framework}

Existing studies have relied on contractual obligations to set the boundary for what management is required. But relational factors are difficult to cover through a contract. Hence, it is important that the archetype framework is able to explain the unwritten obligations and psychological commitments beyond the legal agreement.

Conceptually, we view archetypes as distinct from personality traits or roles. Archetypes are reified as patterns of behavior in an individual's managerial activities. They determine the way in which an individual frames and interprets a situation, how they choose to behave, and what they value.

Archetypes are not personality traits. From a leadership and management perspective, traits are "immutable and not amenable to developmental interventions" [22]. Archetypes are not situational states because the behavior patterns are usually repeated across different settings. Archetypes are neither positional roles nor roles in terms of an individual's knowledge, skills, or abilities [23]. They are not team roles, defined as "a preference to behave in a particular way with other team members" [24].

The concept of a contract management archetype is an instance of what Gioia and Poole describe as scripts or cognitive schemas in organizational behavior; they are schemas that "enable understanding of situations" and a guide to behavior appropriate to those situations" [25]. As cognitive schemas, they are open to revision, change, and developmental intervention. Different organizational actors can develop different schemas and we expect a range of archetypes to be observable. Consistent with the concept of a schema, we expect to be able to explain a large variety of observed behaviors with a finite handful of archetypes, which we have called Contract Management Archetypes (CMAs).

\subsection{Formation of the archetypes}

The CMAs were identified and defined in response to a trans-national, cross-university outsourcing expert session examining why customer firms with similar contracts with similar providers had radically different degrees of satisfaction, conflict, and results. The CMA framework was not derived from theory, but emerged from what Gibbons et al. call Mode 2 knowledge production (contextdriven and problem-focused multidisciplinary teams that work together on specific problems in the real world) [26]. The team drew upon a combined 
experience case base of 2200 cases disseminated in a variety of journals, conferences, and books [27].

We limited the discussion to outsourcing contracts that were similar but had different satisfaction outcomes. We initially categorized actors by identifying and labeling behaviors that were constructive or not. Colloquially we initially labeled these 'goodies' and 'baddies.' It became apparent that many of the 23 behaviors identified were merely extremes of each other. For example, on the baddie side: the customer 'mouse' didn't want to upset the provider and the provider 'obligor' was willing to do whatever the customer wanted even if at odds with provider management. On the goodie side: the customer 'empathizer' took into account the provider's needs and motivations, while the provider's 'trusted colleague' could be relied upon as a sounding board and even mentor. These all eventuated into the first of the archetypes, which we call the Relationship Developer.

In forming the CMAs, we wanted to (1) create a framework specific to business-to-business contractual relationships and (2) limit the explanatory power to where conflict would arise from a difference of values and behavior (as opposed to cases where fault could be determined in a court of law).

A framework of six archetypes, containing both constructive and non-constructive elements, emerged from the observed values and behaviors exhibited by the people that led, developed, and managed contracts. We then examined 100 of our actionresearched cases $^{1}$ to identify conflict/non-conflict between actors and actor-developed artifacts (e.g. contracts, tenders, etc.) and to determine whether more or less CMAs were required to explain resultant situations. During this time, a review of the secondary empirical literature was also conducted with the same aims. This process yielded substantial refinement of the CMAs, but we found that the behavioral dimensions could be accounted for within the six originally identified.

In line with action research approaches comprising field-based testing in an organizational context using real practitioners [28], the CMAs were further refined and tested over the years, in corporate training and actual case settings involving 1092 participants across Asia Pacific and the Americas. This was facilitated by the creation of an online profiling instrument in 2011 (1883 outsourcing practitioner participants as of June 13 2016) which

${ }^{1}$ The 100 cases were used to discover and test more than this construct. provided highly corroborative evidence for the usefulness and relevance of the archetypes.

\subsection{Description of the archetypes}

All six archetypes are useful in different ways, and one is not necessarily better than another. Outsourcing deals are unlikely to fall apart because one of the CMAs is missing from any participant organization. In this way, we do not assert any particular archetype or combination thereof to be a determinant of success. Nor are the CMAs intended to be mutually exclusive at an individual actor level (i.e. one person only has one archetype).

We discuss the archetypes as follows: typifying beliefs and behavior, the value it can bring, and sources of conflict that can occur with that CMA.

\subsubsection{Relationship developer}

Typifying beliefs. The Relationship Developer archetype is characterized by the belief that interpersonal relations, not contracts, make or break deals. Their focus is getting the relationship right via strong rapport, believing that a strong relationship enables cooperation and is a key component of satisfaction with an outsourcing agreement.

Typifying behavior. Relationship Developers are known for concentrating more on socialization (lunches, going for coffee, and the like). To engender trust, sharing personal aspects of oneself such as history, activities, and opinions unrelated to the business matter at hand, having conversations outside of formal ones with timetabled agendas, and otherwise getting to know one another is a priority which must be accomplished early and maintained.

Value. This CMA facilitates trust, respect, and interpersonal relationships. A good relationship yields returns in the form of the ability to discuss matters in an open and candid way. Their building of relationship capital will help to overcome inevitable bumps along the life of a contract.

Conflict. Conflict can occur when overtures made by Relationship Developers are rejected, giving rise to feelings of mistrust in both actors - the Relationship Developer in having the door shut on them, and the rejecter who construes such overtures as an attempt at schmoozing. Relationship Developers, during the course of friendly discourse, also often agree things outside of the written contract that can create downstream issues when left undocumented or not agreed in detail.

\subsubsection{Problem solver}

Typifying beliefs. Problem Solvers view issues as 'hiccups' not obstructions, and like to break down 
barriers that get in the way of what they believe are real results . They have a strong desire to have things operating as smoothly as possible. People operating in this space hold the ability to work through issues as critical and may become annoyed with slow reaction time to issues and slow decision-making.

Typifying behavior. This CMA makes things happen and fix problems. They put out the fires that inevitably occur during contract formation and execution. They fully expect problems to occur and will invest in fixing these as they arise. Many tales of heroism around the outsourcing campfires involve Problem Solvers in rescue mode.

Value. This is the superhero archetype. Problem Solvers are very necessary to make contracts work in practice. Because they rarely care who is to blame for something going wrong - they just want to get it fixed and fixed fast - they join forces without worrying about party lines.

Conflict. In their desire to have things working as smoothly as possible, they can appear as changeresistant, non-strategic, and reactive. Nothing that might create more fires is welcome. Moreover, Problem Solvers have little time or sympathy for bureaucracy or politics. This can result in clashes with those who try to slow them down or mess with stable operations.

\subsubsection{Organizer}

Typifying beliefs. Organizers believe in good documentation, processes, and systems. Organizers spend a fair bit of time developing and/or getting the 'system' working and value compliance with such systems highly.

Typifying behavior. This CMA maintains better records, audit trails, controls, plans, and processes than other archetypes. They often keep notes and retain things others have neglected. This individual often keeps detailed records of any meetings they attend, commonly has a diary in which they record conversations (known as 'file notes'), and frequently keeps hard copies of emails as well as electronic backup.

Value. When neither party can find a signed version of the contract, the necessity of this archetype is glaring. Their emphasis on systemic collection of evidential matter is crucial to the resolution of misunderstandings and possible disputes. They are also heavy users and developers of templates, created to enable efficiency.

Conflict. Organizers can be interpreted as controlling or overly bureaucratic as they impose order and controls over the chaos that they often find during the outsourcing lifecycle. This can be perceived as a fault to others when important matters are held up until the proper paperwork has been completed. The templates and prescribed processes they often require others to comply with can be considered necessary evils, rather than of value.

\subsubsection{Entrepreneur}

Typifying beliefs. Entrepreneurs seek innovation, better ways of doing things, and long-term potential out of the relationship. They are loath to accept explanations of “that's how we've always done it” as a reason to continue to do something a certain way.

Typifying behavior. This individual is a natural disruptor, querying - "why can't we do x?” and "why not try y?" They tend to, at a minimum, identify where improvements are warranted, and often drive continuous improvement initiatives. Thinking outside the box is what they do best.

Value. This CMA sees the most potential in a commercial relationship and can see ineffectiveness without fear or favor. Most importantly, an Entrepreneur is the driver for continuous improvement. It is rare to find a deal that will not benefit from continuous improvement.

Conflict. Individuals with Entrepreneurial inclinations can get frustrated at the lack of new ideas and continuous improvement (despite the contract being silent on this). Change is normal and to be embraced by Entrepreneurs, but may not be welcome by those who are resistant.

\subsubsection{Scanner}

Typifying beliefs. Scanners are information hungry. Driven by their desire to be as informed as possible, they value knowing details of other agreements in their organization and in other organizations, as well as information about individuals in both parties.

Typifying behavior. Scanners are wellnetworked, connected, and natural explorers. They are characterized either by a keen use of the internet (e.g. 'Googling' during meetings, researching after hours in their own time) and/or by having a large number of acquaintances from which they source and share information. Other archetypes can be surprised as to what this individual knows, as the Scanner seems to be familiar with a lot about, say, the personal circumstances of people. To non-Scanners, this might be gossip, but to Scanners it is all part of the knowledge base.

Value. The greatest value of this CMA is bringing the outsourcing world into an otherwise inward focused group. Because they are information seekers, they are natural benchmarkers. Their understanding of contracts will not be limited to only those that the organization currently has. When a firm 
has adopted EBM (Evidence-Based Management) ${ }^{2}$ in its approach to decision making in regards to contracts, Scanners come to the fore.

Conflict. Scanners can overwhelm people with too much data and slow things down while they seek out information. They can also exhaust people in their tireless quest for information, when an individual is the source of the intelligence being sought. For example, one firm controlled a Scanner by limiting the questions she could ask at any one setting to three.

\subsubsection{Monitor Protector}

Typifying beliefs. Monitor Protectors believe parties to a contract must operate at arm's-length and never be perceived to have gotten too close. They also believe that their organization must be protected from the other party, with the contract being a key mechanism to do so.

Typifying behavior. The focus of this CMA is on what risks the other party brings and whether the other party is compliant with the contract. If drafting the contract, they will prepare a one-sided agreement in favor of their party. If in charge of the contract, they prefer to focus on the other party's performance and compliance issues rather than that of their organization.

Value. This CMA sees risks where others do not. When used proactively, to identify potential hazards prior to occurrence, the likelihood of the hazard occurring can be decreased, the effect mitigated, or the treatment agreed rather than disputed. Their efforts on compliance can pay off as well. Aberdeen Group reports that firms with double or more the compliance rate on contracts captured $80 \%$ more savings in their study of 170 enterprises [29].

Conflict. Monitor Protectors are more likely to exhibit asserting/defending interchanges. A Monitor Protector's behavior may resemble that of a bully; being close to recriminations and threats. However, more commonly, the behavior will be a firm and unyielding position - so unyielding, as to be avoided.

\section{Research approach}

We use action research to refine and apply the six CMAs. Action research is an applied research approach linking theory and practice to address practical problems in the field [30]. It comprises a

2 See for example, Pfeffer, J. and Sutton, R., Hard Facts, Dangerous Half-Truths and Total Nonsense: Profiting From Evidence-Based Management, Harvard Business Review Press, 2006. series of cycles in which each cycle consists of four steps: plan, act, observe, and reflect [31].

In the cycle, we first planned an intervention based on the challenge presented to us. We then acted and observed concurrently. We collected contextual information, collected CMA data (through the online instrument completed by all participating actors), analyzed the data and summarized observations, then made initial findings and recommendations. In the field, we continued the 'act' and 'observe' steps during presentations to the participating actors and during solution brainstorming sessions. The act and observe steps concluded with the identification of target actions with the participant actors. Finally, we reflected on both the CMAs and the outcomes of the intervention for the organization.

In this paper, we report action research interventions involving the use of the CMAs within four different cases, each experiencing a different challenge. The constructs and application of the six CMAs evolved throughout the action research cycles, but we focus in this practice-oriented paper on the outcomes of each intervention and the lessons learnt through the application of the archetype framework.

\section{Action research interventions/cases}

In this section, we describe four action research interventions ('cases'). We chose these to demonstrate the application of the CMA framework at different units of analysis (individual, team, organizational, and bi-organizational) as well as represent customer firms and providers in equal measure.

Case 1 is at the individual unit of analysis (focused on a single actor) at a customer firm. Case 2 is at the team unit of analysis at a customer firm involving 34 members within an organizational division. Case 3 is at the organizational level involving 39 actors from two provider divisions. Case 4 is at the bi-organizational level involving 137 actors from the provider and customer firm.

We discuss the cases as follows: firm description, the issue, the CMA observations made, the actions taken as a result, the outcomes of that action, and lessoned learned by the actors.

\subsection{Case 1: Bricks \& Mortar Bank (individual analysis)}

The firm. Bricks \& Mortar Bank was a publically listed bank that grew out of a cooperative building society (it has since merged with another bank of similar size). It was a heavy user of outsourcing services ranging from head office functions such as 
legal, IT, and recruitment, to bank operations such as cash collections and mortgage settlements.

The issue. The Strategic Sourcing Manager was tasked with negotiating a lower price with its provider of travel and online booking services. He first set out to collect as much information as he could on what others were paying for similar services through his personal contacts. Once satisfied that he had collected sufficient evidence that the bank was "paying more than anyone else," he presented the data to the provider and demanded a downward price adjustment. The provider refused. So he then collected more data of a similar nature until he believed it was overwhelming evidence and repeated the demand. This was again rejected.

The CMA observation. It was after completing the online profiling instrument that he realized he had a stronger than normal inclination towards Scanner (in the top quartile) and that he was employing scanning techniques (use of benchmarking data as persuasive evidence) to little effect.

The action. Rather than continue in this mode, he decided to put aside his natural inclination and adopt a different CMA. From the intervention, he learnt that Relationship Developer was the leading preference of actors, and decided to try techniques common to that CMA rather than his preferred methods. This was his weakest and least preferred CMA and he would not normally view an issue through the Relationship Developer lens, nor attempt to resolve it using techniques common to that CMA.

The outcome. He asked the provider if everything was working from their end, and if they had any issues working with the bank's people. After initial hesitation, the floodgates opened. The provider was frustrated that so many refused to use the online system for initial bookings and itinerary changes, booked outside of the provider despite the agreement being exclusive, and staff at the customer care center were being berated above tolerable levels. Under no condition was a discount to be considered when Bricks \& Mortar Bank was breaching the intent of the agreement and being difficult to work with. It was the first time he became aware of the premium that providers can place on customer firms that are difficult to work with, a concept foreign to him at the time. The manager took it as a personal mission to fix this situation. He left with a verbal undertaking to revisit pricing once he formed a solution and that solution began to show positive effects.

Back at the office, after his experience in adapting to this CMA he sees the value, but also knows he is not intuitive operating within it. Relationship Developer was the lowest scoring CMA of the six for this manager and well below that of others (in the bottom 3\% of the 1883 in the CMA database). He seeks relationship-based advice and insight from others in his team prior to embarking on discussions with providers.

The lesson: self-awareness and adaptation are key. One of the important benefits of the CMA framework at the individual level is to develop selfawareness, and from there, recognize the possible need to adapt. In this case, the result was achieved by adapting to the most common CMA.

He realized continuing to "act native" was unlikely to achieve the cost reduction. Two attempts at data as a persuasive tool had "gotten him nowhere and was an act of insanity - doing the same thing over and over again and expecting different results".

When he changed mode to the Relationship Developer archetype, he opened a constructive dialog with the provider crucial to the context.

\section{Case 2: Online Bank (team analysis)}

The firm. Online Bank was founded in 1999 as a completely online bank without branches. As a relatively new entrant in the banking industry, it outsources a significant portion of its operations. Its procurement team of 34 leads the selection and management of its providers. It was with this group that the intervention took place.

The issue. Online Bank's management wanted it to be a "customer of choice" and sought to improve its vendor management. It commissioned a two-day education program for its procurement team, in which a CMA analysis was part.

The CMA observations. The Relationship Developer archetype dominated this group, with nearly $40 \%$ having it as their most preferred mode. They were proud of their relationships and were unanimous in their opinion that providers highly regarded the Bank.

However, this was difficult to maintain. For example, no request for meetings from any provider (current or hopeful) was ever refused. The procurement group was frustrated that they believed they needed to put aside their "real work" to have so many meetings, so often. It limited the time available to perform other responsibilities - so much so, that it became quite contentious during the intervention.

Most insightful for the group was when this was compared to its Organizer scores. Only three of the 34 were in the top quartile and 75\% were below the median ( $\mathrm{n}=1883$ in the CMA database). When presented with this observation, the head of procurement commented that Online Bank had no SLAs (Service Level Agreements) or KPIs (Key Performance Indicators), despite these having been 
standard in the ITO/BPO industry for some time. It is the Organizer archetype that drives systematic documentation and routinized performance measurement, amongst other methodical practices.

The group stated these were not considered important because the relationship was deemed paramount. Such things, it was believed, might upset the relationship. However, when asked what demonstrable value Online Bank was getting from its relationship focus, no answer was forthcoming. The relationship was deemed the outcome, not a means to facilitate outcomes that are more tangible.

The action. As action points, to address the time investment challenge, the bank chose to segment current providers into degrees of importance (high, medium, and low) to give actors guidance on time investment. Potential providers were no longer to be treated the same as current important providers. Rather, regularly scheduled "meet the bank" forums were agreed as a reasonable approach.

To address the value challenge, the bank set up teams to develop KPIs regarding all important provider contracts, and implemented SLAs into its standard contract methodology. In this way, it could begin to measure value with objective data.

The outcome. Within six months of this observation, all key outsourcing contracts had basic SLA and KPI mechanisms put in place by a tiger team of lead Organizers, all of whom were delighted to volunteer for the challenge. The bank subsequently set out to develop standardized measures and agreements to be used from that point forward.

The lesson: preferring one CMA to another has unforeseen consequences. When a firm chooses to promote one CMA above the rest, it must be careful in its choice to ensure that value will be created in doing so. Online Bank discouraged the display of archetypes that were believed damaging to the relationship - namely, Organizer. As a result, it did not receive the benefits of the Organizer archetype either. In recognizing the value of both, it is progressing its measurement and documentation process, as well as no longer discouraging staff that portray the Organizer CMA.

\subsection{Case 3: BPO JV (organizational analysis)}

The firm. BPO JV is a joint venture between a Japanese and an American company providing print equipment and software in addition to ITO services. More recently, it has moved into providing accounts payable BPO, workflow automation, digital creative content, and data analytics.

The issue. BPO JV had a problem closing negotiations. It often took six months to a year to close off a negotiation. This was far longer than the industry norm as told to them by their customers. It resulted in salespeople not receiving commissions on a timely basis. As a result, BPO JV commissioned a national education program called "understanding and negotiation with the customer." A CMA analysis was part of that program.

The CMA observations. Two things were discovered from CMA profiling of the 39 participating actors from BPO JV: (1) the overwhelming archetype within sales was Problem Solver and (2) legal was comprised of Organizers. Nearly 45\% percent in both cases.

It was not so much that BPO JV needed to better understand its customer firms to close a deal; it needed to develop a much more productive way of working between the sales and legal factions. Sales would bespoke each deal to match the needs of the customer, and then legal would restate it to template agreements. The ensuing months were spent trying to reach a compromise with all three stakeholder groups (sales, legal, and the customer firm).

The action. During the intervention, it became obvious to the participating actors at BPO JV that the problem was between two groups - sales and legal. The customer firm was merely unfortunate enough to be caught in the middle. It was a battle between the Problem Solver salespeople and the Organizer legal folks for "the soul of the contract" when a customer firm would not agree to BPO JV's standard contract.

It was established via the intervention that both CMAs have validity but are conflicting in application, expressed by the action researcher to the actor groups as "you both are right, but your customers are suffering when one tries to be the most right." This cleared the way for more constructive dialog on how to balance the two and what internal battles are worth frustrating the customer (at best) and potentially losing the customer (at worst).

The outcome. This dialog triggered a collaborative journey of educating the salespeople on why key contract provisions are there and what options exist, introducing flexibility into the template contract, as well as launching the concept of beginning with a middle ground position, rather than a unilateral one, in the majority of provisions.

The lesson: it's not them, it's us. Although conflict tends to be emphasized as between parties, this conflict exists equally between internal actors. Actors within a single organization will have differing archetype blends and groups of actors will often norm towards a single archetype bias. This bias can be exhibited in outsourcing arrangement artifacts (such as the contract) and result in conflict between different actor groups within the firm. 
The two groups in BPO JV held such strong different CMAs it made it difficult to speak each other's language and understand each other's drivers. But by recognizing equal validity regarding the CMAs those groups normed to, the need to be right dissipated and constructive dialog began.

\subsection{Case 4: Hospitality Group (bi- organizational analysis)}

The firm. Hospitality Group was founded in the UK in 1941 and expanded over the decades to be a major provider of catering and support services employing more than 500,000 people in 50 countries. In this case, they won a tender worth US \$32 million per year for hospitality services including a significant IT component (online bookings, inventory management and reordering, and roster scheduling).

The issue. Things began to go awry shortly after the contract was signed. Operations began spotty and got worse (eventually resulting in formal default). Even though operations were struggling, the provider was focused on delivering the innovation called for in the customer's request for tender (RFT). In the first year, they submitted numerous proposals. All were rejected. The frustration some of business unit senior executives were feeling was expressed by one as, "They are focused on selling more stuff to us, not delivering what they had already sold."

The CMA observations. The strategic sourcing group within the customer firm, which issued the RFT, had three times as many Entrepreneurs than the business units they were representing. The provider unconsciously stocked the management team to match the RFT with Entrepreneurs (three times that typically present in providers $(n=347$ provider participants in the CMA database).

But after contract award, strategic sourcing handed the deal over to be managed by the business, dominated by Relationship Developers. The only 'innovation' the business was interested in was cost savings, not any of the creative ideas proposed in the provider's bid or subsequently.

The action. Once the intervention identified the CMA differences of the customer groups pre and post contract, it became obvious to Hospitality Group that the goalposts had changed and they must too. It realized it had staffed its team to deliver to the RFT, rather than the business, it quickly changed tack. All innovation stopped, leadership pairing to key customer actors took place, and the emphasis put on relationship development and operations delivery.

The outcome. The relationship reset began to yield results within months, culminating in an extended contract and what was described by
Hospitality Group's CEO as the "greatest turnaround in our history."

The pairing was a key initiative that opened dialog that had never previously occurred and created the basis of personal trust. The new leadership pairs, and the chemistry between them, enabled the parties to rethink everything about the deal.

In 2015, a new contract was signed after six months work on radical transformation of the contract and governance structure. It is now the ideal model promoted by both parties in other agreements.

The lesson: winning vs. doing - change archetype decisions. Outsourcing has a lifecycle and there will be many actors involved as an arrangement moves through it. These actors are likely to have different CMA mixes and corresponding expectations that necessitate a change in strategy throughout the life of a relationship. Differentiating what CMAs need to be at the fore to win vs. deliver can make or break a relationship when entire groups of the customer firm are only present a single juncture.

Management understood that customer firms have many stakeholders, and stakeholder groups, that must be catered to. This was the first time; however, that management realized that tender documents might reflect the desires of one group over the majority.

Management has taken this lesson to a similar situation on a much larger contract where the contract was developed and awarded by a group was different from the service recipient businesses. It is treating that contract as a framework rather than a bible, and has begun discussions with each business to form a bespoke supplementary agreement specific to each.

\section{Discussion}

\subsection{Cross-case lessons}

Self-awareness of one's own CMA preferences, and those of others, was shown in the cases to be an important ingredient in goal attainment, inter-group efficiency, and relationship progress. Coupled with the recognition that none is inherently right or wrong, this opened dialog between previously conflicting actors.

Each archetype comes with a set of underlying values that may not be shared, and can be quite different, from another archetype. At a group unit of analysis, this can give rise to conflicts in which group members can misunderstand, even resent, other groups or individuals within their own group with archetypes different to their own. Whether the conflict is between parties or within a party - both can have severe consequences as shown in the cases.

In each case, CMA self-reflection led to a change in management approach. Although each case had 
different issues and solutions, recognizing the value of different CMAs facilitated the depersonalization of conflict in all. This led to the ability to develop more efficient and relationship-bolstering approaches.

\subsection{Implications}

For practice. The CMAs represent what people believe is important and how they approach contracts. Each is valuable - the relationship should be good, problems should be solved, records should be kept, there should be continuous improvement, information should drive decisions, and risks should be mitigated. A balanced portfolio of archetypes, and the ability to adapt to non-preferred ones, promises to yield more productivity in the long term, and greater satisfaction between the parties as a whole.

But no one person can exhibit all CMAs in equal measure all of the time. If one holds a certain set of values, but a colleague in the other party does not, or has a different set altogether, conflict can result. Awareness of the value and legitimacy of the different archetypes triggered positive results in the cases and offers promise to do likewise for others.

These archetypes were used to address outsourcing issues and alter non-malicious conduct to achieve positive outcomes. The results suggest that a successful outsourcing engagement can be derived through adaptation of behavioral approaches rather than contracting techniques. By exemplifying CMA application and adaptation in multiple units of analysis, we believe organizations that are looking to start or further develop their outsourcing relationships, may weigh these archetypes to see which is best for each specific contract relationship.

For research. The CMA framework offers researchers a new mechanism to explore outsourcing relationships at a personal, team, and organizational level within and between parties.

Further work on the construct validity of the framework is an obvious avenue for further research. Perhaps less obvious, but important to the practitioner community, is establishing whether certain archetypes are best suited for particular contexts, positions, or goals. This has been requested by numerous participants who have participated in CMA analysis over the years.

Another consists of comparatives to other conflict sources such as that in agency theory regarding conflicts of interest and moral hazard. Also identified is the exploration of the degree to which the CMA typifies psychological contracts as generally described in an outsourcing context by Koh et al. [32] and how perceptions of breaches thereof drive trust more so than breaches of the written contract.

\section{Conclusion}

This paper proposes the CMA framework as a means of investigating outsourcing relationships at an individual actor level, which can then be analyzed more broadly into groups and organizations when archetype data is collected at those levels. It used the proposed CMA framework to explore challenges, relationship dynamics, and the results of applying the framework in four action research cases.

Although action research offers a means of investigating complex social units consisting of multiple variables anchored in real-life situations [33], the issue of generalizability looms larger here than with other types of qualitative research [34]. The researcher is the primary instrument of data collection and analysis introducing subjectivity of the researcher and others involved in the case; however, the question of subjectivism and bias toward verification applies to all methods, not just to qualitative research approaches [35].

Further action research is planned in the form of a single in depth case, exploring actors from the individual to organizational units of analysis.

We have also collected data on 1883 actors since the online CMA instrument was developed. We envision exploratory demographic work useful to the practice community (e.g. customer firm vs. provider, executive level vs. non-executive, and government vs. commercial sector) to gather insights into challenges between the demographics.

Lastly, we plan to explore the CMAs with other archetypical instruments including the Thomas Kilmann Instrument (indicates behavior in conflict situations [36]), or the Myers-Briggs Type Indicator (indicates preferences in how people perceive things and judge what has been perceived [37]).

\section{References}

[1] The size of the UK outsourcing market across the private and public sectors, Oxford Economics, London, 2010.

[2] State of the Outsourcing Industry 2013, HFS Research/KPMG, Boston, 2013.

[3] 2016 Global Outsourcing Survey, Deloitte Consulting.

[4] Kappelman, L., McLean, E., Johnson, V. and Torres, R. "The 2015 SIM IT Issues and Trends," MISQE 15:1, 2016, 55-83.

[5] Dibbern, J., Goles, T., Hirschheim, R. and Jayatilaka, B., "Information systems outsourcing: A survey and analysis of the literature," Data Base for Advances in Information Systems 35:4, 2004, 6-102. 
[6] Lacity, M., Khan, S., Yan, A. and Willcocks, L., "A Review of the IT Outsourcing Empirical Literature and Future Research Directions," Journal of Information Technology 24:4, 2010, 395-433.

[7] Earl, M.J., "The Risks of Outsourcing IT," Sloan Management Review 37:3, 1996, 26-32.

[8] Klepper, R. and Jones, W.O., Outsourcing Information Technology Systems \& Services, NJ: Prentice Hall, 1998.

[9] Lacity, M. and Willcocks, L., "An Empirical Investigation of Information Technology Sourcing Practices: Lessons from Experience," Management Information Systems Quarterly 22:3, 1998, 363-408.

[10] Lee, J.-N., Miranda, S.M. and Kim, Y.-M., "IT Outsourcing Strategies: Universalistic, Contingency, and Configurational Explanations of Success," Information Systems Research 15:2, 2004, 110-131.

[11] Huber, T., Fischer, T., Dibbern, J., and Hirschheim, R., "A process model of complementarity and substitution of contractual and relational governance in IS outsourcing," Journal of Management Information Systems 30:3, 2013, 81-114.

[12] Lacity, M., Khan, S., and Willcocks, L., "A review of the IT outsourcing literature: Insights for practice," Journal of Strategic Information Systems 18:3, 2009, 130-146.

[13] Drodenbaugh quoting the Aberdeen Group, "The Outsourcing Low Cost Lie," 2010. http://www.lessonsoffailure.com/tag/project-costs/

[14] St. John, J., Guynes, C.S., and Vedder, R., "The Client-Vendor Offshore Relationship: Success Factors," Information Systems Management 31:2, 2014, 120-125.

[15] Kim, H.J., Shin, B. and Lee, H., "The Mediating Role of Psychological Contract Breach in IS Outsourcing: InterFirm Governance Perspective," European Journal of Information Systems 22:5, 2013, 529-547.

[16] Cullen, S., The Contract Scorecard: Successful Outsourcing by Design, Gower, London, 2009.

[17] Lacity, M. and Willcocks L., Advanced Outsourcing Practice: Rethinking ITO, BPO and Cloud Services, Palgrave, London, 2012.

[18] Whitten, D. and Leidner, D., "Bringing IT Back: An Analysis of the Decision to Backsource or Switch Vendors," Decision Sciences 37:4, 2006, 605 - 621.

[19] Scope Aggregation in Outsourcing: Why the Strong Get Stronger, Everest Research Institute, Dallas, 2007.

[20] Lacity, M.C., Khan, S.A. and Willcocks, L.P "Leadership Pairs: Behind High Outsourcing Performance," Pulse, IEEE, NY, 2014, 52-57.

[21] Hill, J.A., Eckerd, S., Wilson, D., and Greer, B., "The Effect of Unethical Behavior on Trust in a Buyer-Supplier Relationship: The Mediating Role of Psychological
Contract Violation," Journal of Operations Management 27:4, 2009, 281-293.

[22] Zaccaro, S.J., "Trait-based perspectives of leadership," American Psychologist 62:1, 2007, 6-16.

[23] Mathieu, J.E., Tannenbaum, S.I., Donsbach, J.S., and Alliger, G.M., "A review and integration of team composition models moving toward a dynamic and temporal framework," Journal of Management 40, 2014, $130-160$.

[24] Aritzeta, A., Swailes, S. and Senior, B., "Belbin’s team role model: Development, validity and applications for team building," Journal of Management Studies 44, 2007, 96-118.

[25] Gioia, D.A. and Poole, P.P., "Scripts in Organizational Behavior," Academy of Management Review 9:3, 1984, 449-459.

[26] Gibbons, M., Limoges, C., Nowotny, H., Schwartzman, S., Scott, P., and Trow, M., The new production of knowledge: the dynamics of science and research in contemporary societies, Sage, London, 1994.

[27] Cullen, S., Lacity, M. and Willcocks, L., Outsourcing: All You Need to Know, White Plume Publishing, Melbourne, 2014.

[28] Wynekoop, J.L and Russo, N.L., Studying systems development methodologies: an examination of research methods, Information Systems Journal 7:1, 1997, 44-77.

[29] Browning, W., "Procurement Contracts: Real Value, Real Returns", Aberdeen Group, March, 2009.

[30] Baskerville, R.L. and Wood-Harper, A.T., "A critical perspective on action research as a method for information systems research," Journal of Information Technology 11:3, 1996, 235-246.

[31] Moody, D. and Shanks, G., "Improving the quality of ER models: empirical validation of a quality management framework," Information Systems 28:6, 2003, 619-650.

[32] Koh, C., Ang, S. and Straub, D.W., "IT Outsourcing Success: A Psychological Contract Perspective," Information Systems Research, 15:4, 2004, 356-373.

[33] Merriam, S.B., Qualitative Research: A Guide to Design and Implementation 3rd ed, Jossey-Bass, San Francisco, 2009.

[34] Hamel, J., Case Study Methods, Sage, London, 1993.

[35] Flyvberg, B., "Five misunderstanding about case-study research," Qualitative Inquiry 12:2, 2006, 219-245.

[36] An Overview of the TKI, Kilmann Diagnostics, retrieved June 112016.

[37] MBTI basics, Myers-Briggs Foundation, retrieved June 112016. 